\title{
Analysis of deformation and microstructure evolution during the cogging process of Waspaloy alloy
}

\author{
Marcin Kukuryk ${ }^{1, *}$, Jerzy Winczek ${ }^{1}$, Marek Gucwa ${ }^{1}$ \\ ${ }^{1}$ Czestochowa University of Technology, 42-201 Czestochowa, Poland
}

\begin{abstract}
The hot deformation behavior of Waspaloy alloy has been investigated by two-pass hot cogging process. The paper presents theoretical end experimental analysis of deformations and microstructural evolutions. The results of a thermo-mechanical simulation for the spatial hot cogging process on the shaped anvils with the application of the threedimensional finite element method, are presented. The numerical calculation gave an assessment of the effective strain, mean stress and temperature distributions in the work-piece. Models for predicting the evolution of microstructure were developed for dynamic recrystallization and grain growth phenomena. The influence of shape of the anvils on the grain size after dynamic recrystallization was analyzed. The numerical analysis was performed using a commercial program "DEFORM - 3D" with thermo-mechanical and microstructural evolution coupled. The results are compared with the experimental data, a good agreement between the predicted and experimental results was obtained.
\end{abstract}

Keywords: cogging, Waspaloy alloy, strain, microstructure, FEM

\section{Introduction}

Waspaloy is a nickel-based alloy that enables the transfer of fast-variable load cycles, allows operation at elevated temperatures while retaining high and stable mechanical properties (up to $650^{\circ} \mathrm{C}$ ), and has high resistance to aggressive media under high stress (up to $500 \mathrm{MPa}$ ). The majority of high-strength constructional elements of this alloy are made by hot plastic working method, whereby they are subjected to open or closed-die forging and heat treatment to achieve the required microstructure [1]. The capability to ensure the narrowed dimensional tolerance ranges and optimal shapes of products, combined with good high-temperature creep resistance and heat resistance, makes forgings produced by this means find increasingly wide application in the aircraft and rocket industries (shafts, plates, rings and casings), nuclear power engineering and in machinery and machine tools operating under heavy-duty conditions [2].

\footnotetext{
${ }^{*}$ Corresponding author: kukurykm@itm.pcz.pl

Reviewers: Mariana Pajtášowá, Dominik Wilczyński
} 
Forging nickel-based alloys is largely hampered due to their low ductility and high resistance during deformation at elevated temperatures. Their high flow stress and high recrystallization temperature narrow the forging temperature range to $1000-1100^{\circ} \mathrm{C}$, hence the implementation of forging technologies for these alloys still faces a number of major technological problems [3]. For developing the optimal thermo-mechanical deformation conditions for nickel-based alloys in order to obtain the required microstructure in finished products under industrial conditions, simulations of the process of forging at high deformation temperatures, considering variable process parameters (temperature, strain and strain rate), are necessary [4]. By controlling changes in the thermo-mechanical state of the deformation zone in the Waspaloy alloy blank forging process, the mechanical and functional properties of products can be significantly influenced. A. Chamanfar et al. [5] propose also to take account of the influence of friction and adiabatic heating on the flow stress during plastic forming of the Waspaloy alloy.

A considerable part of studies on the microstructure of Ni-based superalloys examine the process of dynamic recrystallization as a function of temperature, strain and strain rate [6-7]. The deformation temperature has a significant influence on the size of grains formed as a result of dynamic recrystallization, with the grain shape and size being able to be changed in a wide range, thus influencing on the structure and mechanical properties of the forgings. Because of high contents of alloying constituents in Waspaloy and a relatively narrow range of forging temperature, strict adherence to the set technological conditions is required in the process of modifying the initial ingot microstructure.

A finite element method-based model has been developed in this study, which enables the simulation of the metal flow pattern, thermal phenomena and microstructure development in the process of forging Waspaloy on shaped anvils. The effect of tool shape and forming conditions on the metal flow kinematics, and the distribution of strain, stress and temperature has been established, and the distribution of grain size in individual forging regions has been determined. This course of action allows an improvement in the quality of cogged Waspaloy bars with a possibility of predicting the internal quality.

\section{The material model and experimental procedures}

A three-dimensional finite element method was used in the simulation of metal flow and heat transfer during the process of forging of the Waspaloy alloy. For the analysis of the cogging process using DEFORM 3D software, with thermo-mechanical and microstructural evolution coupled. The basic equations to be satisfied are the equilibrium equation, the incompressibility condition, and the constitutive relationship. According to the variational principle, the basic equation for the finite-element formulation is expressed as:

$$
\delta \phi=\int_{V} \bar{\sigma} \delta \dot{\bar{\varepsilon}} d V+\int_{V} K \dot{\varepsilon}_{v} \delta \dot{\varepsilon}_{v} d V-\int_{S} F_{i} \delta v_{i} d S=0
$$

where : $\bar{\sigma}$ is the effective stress, $\bar{\varepsilon}$ is the effective strain, $\dot{\bar{\varepsilon}}$ is the effective strain rate, $\dot{\varepsilon}_{v}$ is the volumetric strain rate, $K$ is a penalty constant that is a very large positive constant, $F_{i}$ is the force on the boundary surface of $S$, and $V$ and $S$ are the volume and surface of a deforming workpiece, respectively.

The temperature distribution of the workpiece in the analysis of heat transfer can be obtained by solving the following energy balance equation:

$$
k \nabla^{2} T+q-\rho c \frac{\partial T}{\partial t}=0
$$


where: $k, \rho, c, q, T$ and $t$ denote the thermal conductivity, specific density, specific heat, heat generation rate, temperature and time, respectively. The first term $k \nabla^{2} T$ and the third term $\rho c T$ represent the heat transfer rate and the heat generation rate, respectively. Due to plastic deformation, the rate of the heat generation in the deformed body is given as:

$$
q=\alpha \bar{\sigma} \bar{\varepsilon}
$$

where $\alpha$ is the efficiency of plastic deformation work converting into heat, and the value is generally taken as 0.90 . The energy balance equation, Eq. (3), can be rewritten using the weighted residual method as:

$$
\int_{V} k T_{, i} \delta T_{, i} d V+\int_{V} \rho c \dot{T} \delta T d V-\int_{V} \alpha \bar{\sigma} \dot{\bar{\varepsilon}} \delta T d V-\int_{S} q_{n} \delta T d S=0
$$

where $q_{n}$ is the heat flux normal to the boundary surface, including heat loss to the environment and friction heat between two contacting objects.

The effect of friction at the anvil-workpiece interface can be considered by the following equation:

$$
f=-\frac{2}{\pi} m k \operatorname{arctg} \frac{\left|V_{s}\right|}{u_{0}} t
$$

where $m$ is the friction factor $(0 \leq m \leq 1), u_{0}$ is a very small positive number compared to $/ V_{s} /, V_{s}$ is the velocity vector of the workpiece relative to the anvil, $k$ is the local flow stress in shear and $t$ the unit vector in the direction of $V_{s}$.

The flow stress values for the Waspaloy alloy were taken based on plastometric tests carried out for different values of true strain (0.105-0.693) and strain rates $\left(0.10-1.0 \mathrm{~s}^{-1}\right)$, and for a fixed range of hot plastic working temperature (1173-1423K). The obtained results allowed the determination of flow stress values, as dependent on the true strain, strain rate and temperature, which were input to the program with the aim of evaluating the best rheological model for the material being deformed $(\bar{\sigma}=f(\varepsilon, \dot{\varepsilon}, T))$. The flow curves for lowest $\left(0.10 \mathrm{~s}^{-1)}\right.$ and highest $\left(1.0 \mathrm{~s}^{-1}\right)$ strain rate conditions are shown in Fig. 1. It can be clearly seen that the flow stress increases to a maximum during high temperature deformation. After attaining a peak value, the stress decreases until it reaches a steady state. This is an indication that the material softens by dynamic recrystallization.
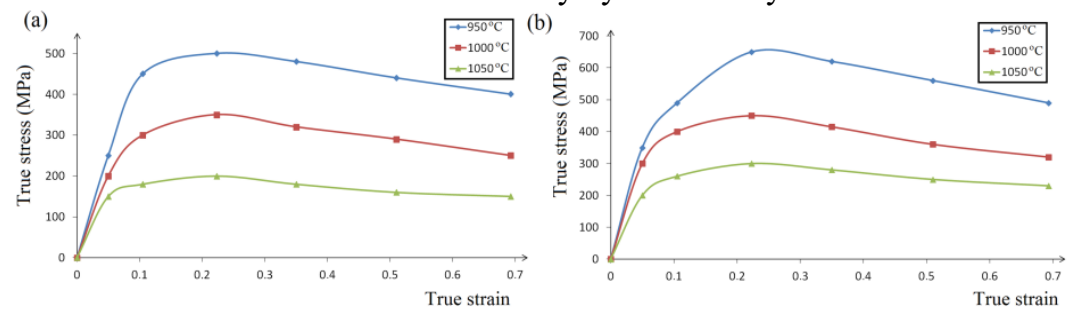

Fig. 1. Variation of flow stress for the Waspaloy alloy as a function of true strain and temperature for different strain rate values, i.e.: (a) $\dot{\varepsilon}=0.1 s^{-1}$ and (b) $\dot{\varepsilon}=1 s^{-1}$

In the hot cogging process, microstructure change takes place easily through the deformation of the material. The microstructure change occurring due to deformation is generally called dynamic recrystallization. The following equation is widely applied to describe the DRX kinetics [8-9]. 


$$
\begin{aligned}
& \varepsilon_{c}=a_{1} a_{2} \dot{\varepsilon}^{m_{1}} \exp \frac{Q_{1}}{T} \\
& X_{D R X}=1-\exp \left[-\ln 2\left(\frac{\varepsilon-\varepsilon_{c}}{\varepsilon_{0.5}-\varepsilon_{c}}\right)^{k_{d}}\right] \\
& \varepsilon_{0,5}=a_{1} \dot{\varepsilon}^{m_{1}} \exp \frac{Q_{1}}{T} \\
& d_{D R X}=a_{3} \dot{\varepsilon}^{m_{2}} \exp \frac{Q_{2}}{T}
\end{aligned}
$$

where $\varepsilon_{c}$ is the critical recrystallization strain, $T$ is the deformation temperature (unit: $\mathrm{K}$ ), $\mathrm{X}_{\mathrm{DRX}}$ is the DRX volume fraction, $\varepsilon$ is the true strain, $\dot{\varepsilon}$ is the strain rate, $\varepsilon_{0.5}$ is the strain for $50 \% \mathrm{DRX}, d_{D R X}$ the dynamically recrystallized grain size, $a_{1}, a_{2}, a_{3}, m_{1}, m_{2}, k_{d}, Q_{1}$ and $Q_{2}$ are the material constans. $\varepsilon_{c}$ and $\varepsilon_{0.5}$ can be expressed as the functions of Zener-Hollomon parameter [10]. Some more important values of the determined coefficients occurring in formulas (6)-(7) are as follows: $a_{1}=6.3993 \times 10^{-6}, a_{2}=0.2565, a_{3}=10897, m_{1}=0.14587$, $m_{2}=-0.141, k_{d}=1.505, Q_{1}=15998.439, Q_{2}=8499.829$.

In numerical computations and in experimental tests, $\varnothing 80 \mathrm{~mm}$-diameter and $150 \mathrm{~mm}$ long stock made of the Waspaloy alloy was taken. The initial deformed material temperature was taken to be $1323 \mathrm{~K}$, and the anvil temperature was assumed to be equal to $573 \mathrm{~K}$, i.e. the anvil heating temperature in industrial conditions. Forging experiments were conducted for three of applied anvils by using a hydraulic press (maximum load 2.5 MN). The original grain size before forging of the specimens was $d_{0}=100 \mu \mathrm{m}$. Forging was carried out in two consecutive reductions with tilting the workpiece by an angle of $90^{\circ}$, while retaining a constant value of the reduction ratio (true $\varepsilon_{h}=0.35$ ) and a constant relative feed of $l_{w}=0.75$. The cogging process was conducted in convex - trapezoid anvils, asymmetrical combined anvils with an angle of $75^{\circ} \times 60^{\circ}$, and $V$-shaped anvils with an angle of $135^{\circ} \times 135^{\circ}$, as shown in Figure 2 . 
(a)

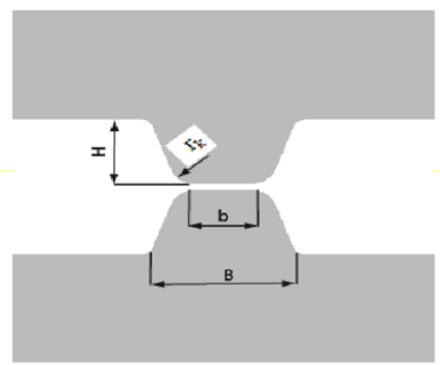

(b)

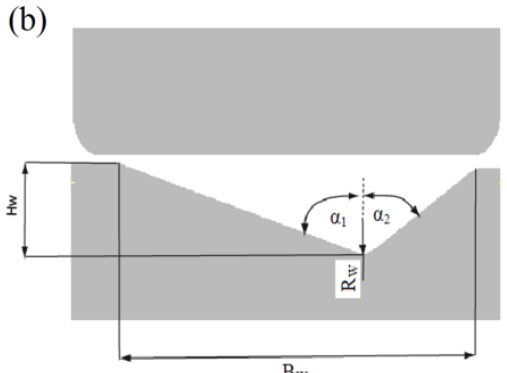

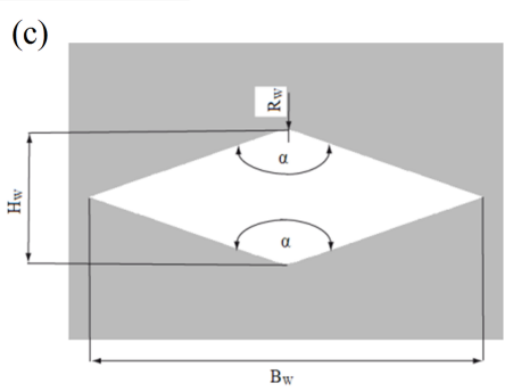

Fig. 2. Shape of anvils: (a) convex - trapezoid $\left(b=35.0 \mathrm{~mm} ; B=56.0 \mathrm{~mm} ; H=40.0 \mathrm{~mm} ; r_{k}=5.0\right.$ $\mathrm{mm})$, (b) asymmetrical combined with an angle of $\alpha_{1}=75^{\circ}$ and $\alpha_{2}=60^{\circ} \quad\left(R_{w}=28.0 \mathrm{~mm} ; H_{w}=25.3\right.$ $\left.\mathrm{mm} ; B_{w}=138.0 \mathrm{~mm}\right)$, (c) $V$-shaped with an angle of $\alpha=135^{\circ}\left(R_{w}=28.0 \mathrm{~mm}, H_{w}=60.5 \mathrm{~mm}\right.$; $\left.B_{w}=146.5 \mathrm{~mm}\right)$

\section{Results and discussion}

The investigation has determined the local values characterizing the strain and stress state, temperature distribution, and the distributions of the dynamically recrystallized volume fraction and the average grain size in the specimen volume during cogging on convex trapezoid anvils, asymmetrical combined anvils with an angle of $75^{\circ} \times 60^{\circ}$ and on V-shaped anvils with an angle of $135^{\circ} \times 135^{\circ}$.

The distribution of effective strain, average stress and temperature after the second technological pass $\left(\varepsilon_{h}=0.70\right)$ on the convex trapezoid anvils is shown in Fig. 3 . The largest effective strain values covered the predominant region of the central deformation zone part, amounting to $(\bar{\varepsilon}=0.875-1.00)$ (Fig. 3a). The region adjacent to the anvil surfaces and the side forging zones were the location of smaller strains $(\bar{\varepsilon}=0.625-0.750)$. On the cross-sectional surface of the forging (except for dead corners), the absence of tensile stress was found (Fig. 3b). Due to low thermal conductivity, the temperature in a fairly large region of the central forging part did not change as deformation progressed. The contact of the hot metal with the cooler tools caused a temperature drop near the contacting surfaces by $80-100^{\circ} \mathrm{C}$ (Fig. 3c). 
(a)

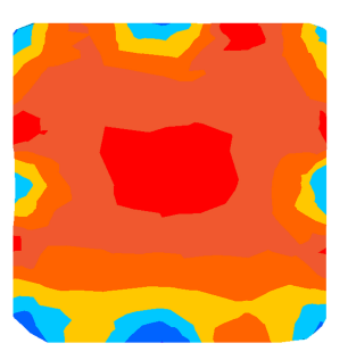

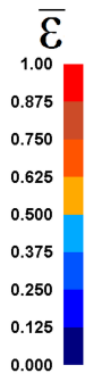

(b)

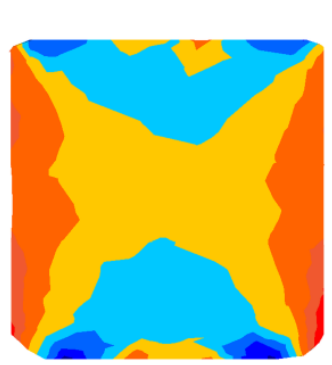

$\mathrm{MPa}$

50.0

6.25

$-37.5$

$-81.3$

$-125$

$-169$

$-213$

$-256$

(c)

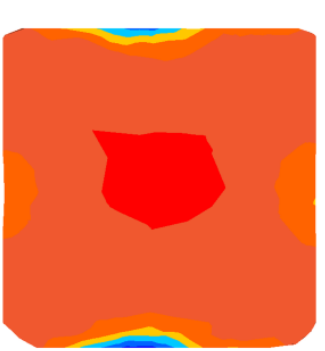

${ }^{1100} \mathrm{C}$
${ }^{1080}$
1060
1040
1020
995
973
952
931

Fig. 3. Distribution of effective strain (a), mean stress (b) and temperature (c) on the cross-sectional surface of the specimens after cogging process in convex-trapezoid anvils. The reduction ratio of $\varepsilon_{h}=0.70$

Figure 4 shows the distributions of effective strain, mean stress and temperature after cogging of Waspaloy specimens on the asymmetrical combined anvils with an angle of $75^{\circ} \times 60^{\circ}$ after the second technological pass $\left(\varepsilon_{h}=0.70\right)$. In the axial forging zone, the maximum values of effective strain $\bar{\varepsilon}$ considerably exceeded the preset reduction value, amounting to $\bar{\varepsilon}=1.13-1.31$, which favoured the plastic working of the forging. The region adjacent to the anvil surfaces and the side forging zones were the location of smaller effective strains, which amounted to $\bar{\varepsilon}=0.375-0.563$ (Fig. 4a). The relatively large surface of contact between the deformed material and the tool is the reason for the occurrence of compressive stress in the central forging part (Fig. 4b). The presented distribution of mean stress suggests the possibility of tensile stress occurring only in the side zones of the forging. The forging process was accompanied by stable temperature in the central forging part, which was caused by the release of plastic deformation heat and the low thermal conductivity. Only on the contact surfaces between the deformed material and the anvils were temperature drops by $80-100^{\circ} \mathrm{C}$ observed (Fig. $4 \mathrm{c}$ ). 
(a)

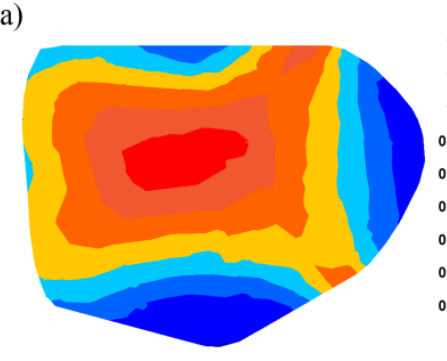

(c)

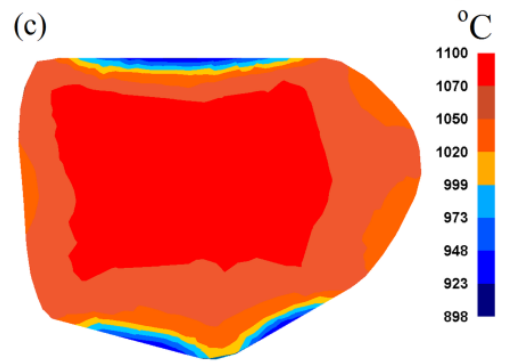

(b)
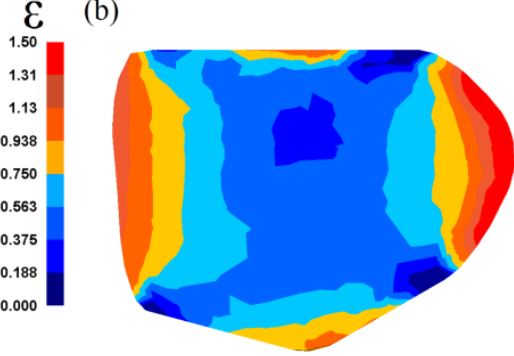

$\mathrm{MPa}$
100
43.8
.12 .5
.68 .8
-.25
-181
.238
-294
.350

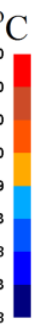

Fig. 4. Distribution of effective strain (a), mean stress (b) and temperature (c) on the cross-sectional surface of the specimens after cogging process in asymmetrical combined anvils with an angle of $75^{\circ} \times 60^{\circ}$. The reduction ratio of $\varepsilon_{h}=0.70$

Figure 5 depicts the distributions of effective strain, mean stress and temperature on the cross-sectional surfaces of a Waspaloy forging after cogging in $\mathrm{V}$-shaped anvils with an angle of $135^{\circ} \times 135^{\circ}$ in two technological passes $\left(\varepsilon_{h}=0.70\right)$ with inter-operational rotation by an angle of $90^{\circ}$. The largest effective strain occurred in the axial zone of the forging ( $\bar{\varepsilon}=1.40-1.60$ ), which had a favourable effect on its plastic working (Fig. 5a). The zones neighbouring on anvil corner roundings and at the side forging surfaces were a region of smaller effective strain, which was equal to $\bar{\varepsilon}=0.80-1.00$. The issue of the correct and, at the same time, uniform distribution of effective strain within the forging volume was an important factor from the point of view of obtaining the required and homogeneous structure during plastic forming on those anvils. The presented distribution of mean stresses (Fig. 5b) indicates a possibility of tensile stress arising only in very small regions in the side zones of the forging. The investigation has confirmed the advisability of using these anvils for cogging the Waspaloy alloy, because the modification of the technology can be carried out with a high uniformity of effective strain distribution and in an advantageous triaxial compression state. Under such conditions, the primary structure can be completely forged out and recrystallized in the cogging process. The temperature distribution was similar to that on the previous tools (Fig. 5c). Experimental measurements of temperature at selected points on the surface of an as-deformed forging using a thermovision camera showed an agreement between the measured and calculated temperatures (with a difference of $\left.\pm 8^{\circ} \mathrm{C}\right)$. 

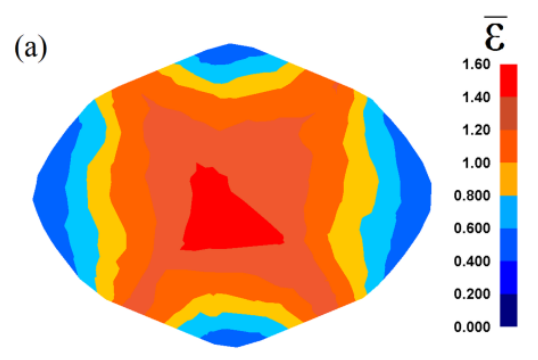

(b)
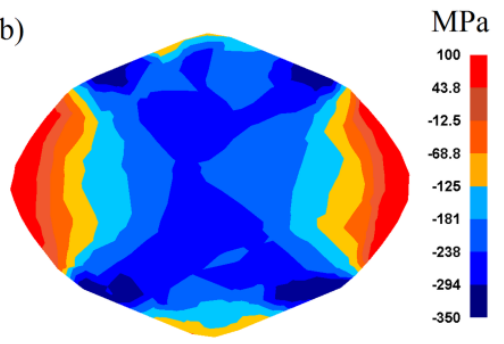

(c)
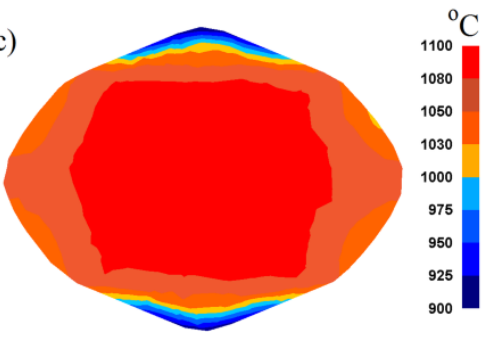

Fig. 5. Distribution of effective strain (a), mean stress (b) and temperature (c) on the cross-sectional surface of the specimens after cogging process in $V$ - shaped anvils with an angle of $135^{\circ} \times 135^{\circ}$. The reduction ratio of $\varepsilon_{h}=0.70$

The distribution of the dynamically recrystallized volume fraction and average grain size after cogging on convex trapezoid anvils (after the second pass) is illustrated in Fig. 6. Dynamic recrystallization started in a large portion of the region subjected to deformation, and a fraction of the dynamically recrystallized volume reached its maximum in the middle of the forging, amounting to 0.750 , which resulted the smallest grain size in that region (50$60 \mu \mathrm{m})$. The area adjacent to the anvil surfaces and the side forging zones were a region of smaller dynamically recrystallized volume fraction values $(0.375-0.500)$ and correspondingly larger grain sizes $(75-87.5 \mu \mathrm{m})$.

(a)

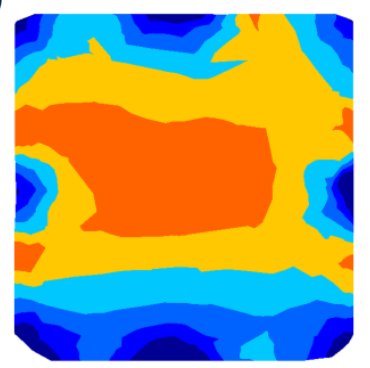

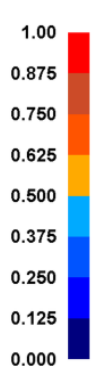

(b)

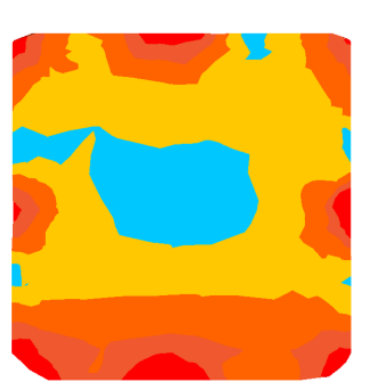

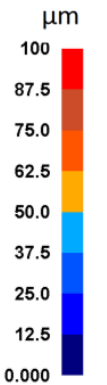

Fig. 6. Distribution of the dynamically recrystallized volume fraction (a) and average grain size (b) on the cross-sectional surface of the specimens after cogging process in convex-trapezoid anvils. The reduction ratio of $\varepsilon h=0.70$

Figure 7 shows the distribution of the dynamically recrystallized volume fraction and average grain size on the cross-sectional surfaces of Waspaloy specimens after cogging on combined asymmetric anvils. The dynamically recrystallized volume fraction attained its maximum in the forging centre and amounted to 0.875-1.00 (Fig. 7a) and, as a consequence, the smallest grain size in this region, amounting to 25.0-37.5 $\mu \mathrm{m}$ (Fig. $7 \mathrm{~b}$ ). The area adjacent to the anvil surfaces and the side forging zones were a region of smaller 
dynamically recrystallized volume fraction values $(0.250-0.375)$ and correspondingly larger grain sizes $(75.0-87.5 \mu \mathrm{m})$.

(a)

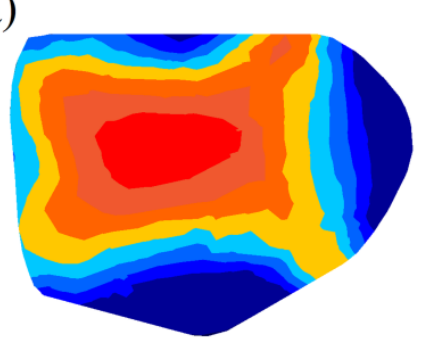

(b)

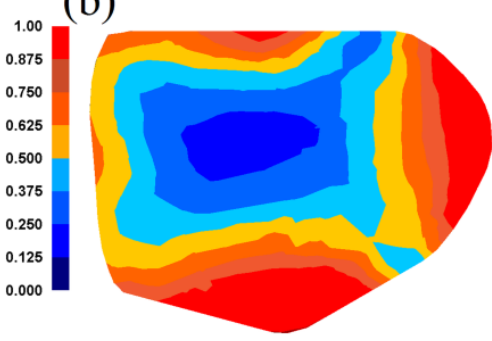

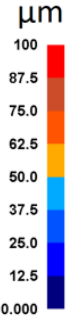

Fig. 7. Distribution of the dynamically recrystallized volume fraction (a) and average grain size (b) on the cross-sectional surface of the specimens after cogging process in asymmetrical combined anvils with an angle of $75^{\circ} \times 60^{\circ}$. The reduction ratio of $\varepsilon h=0.70$

Figure 8 illustrates the distributions of the dynamically recrystallized volume fraction and average grain size on the cross-sectional surfaces of Waspaloy specimens after cogging in V-shaped anvils with an angle of $135^{\circ} \times 135^{\circ}$ in two technological passes $\left(\varepsilon_{h}=0.70\right)$ with inter-operational rotation by an angle of $90^{\circ}$. The dynamically recrystallized volume fraction attained its maximum in the forging centre and amounted to 0.875-1.00 (Fig. 8a), which resulted in the smallest grain size in this region, amounting to $25.0 \mu \mathrm{m}$ (Fig. 8b). In the second technological pass, owing to maintaining a stable temperature and attaining large effective strain values in the axial forging zone, the dynamic recrystallization process covered the predominant portion of the plastic zone volume, and the grain size was significantly reduced after dynamic recrystallization. During cogging in V-shaped anvils, due to an intensive plastic working, the smallest grain size was obtained in the axial forging section, compared to other tools under investigation. A twofold larger average grain size was obtained in the forging centre during cogging on convex trapezoid anvils, while on combined asymmetrical anvils, a grain size greater by $50 \%$ was obtained in that zone. The investigation has confirmed the advisability of using $\mathrm{V}$-shaped anvils for cogging the examined nickel alloy, because the modification of the plastic working technology will be effective and will be able to be carried out in an advantageous triaxial compression state. The primary structure in the process of cogging on these tools was completely forged out and recrystallized. No high forging ratios are foreseen during finishing die forging process.
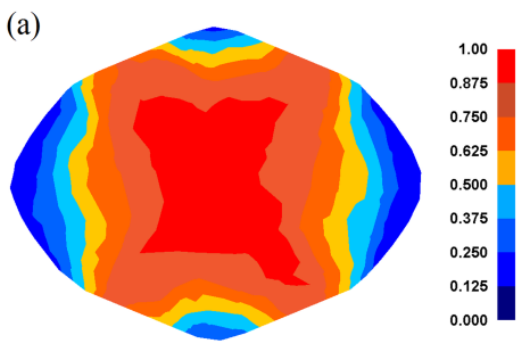

(b)

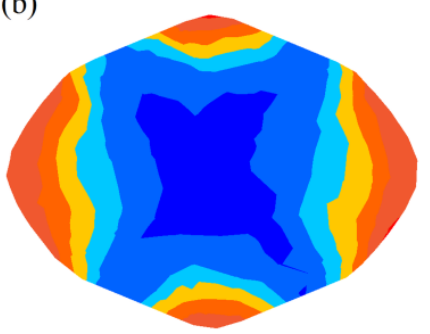

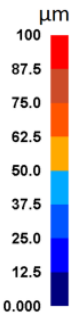

Fig. 8. Distribution of the dynamically recrystallized volume fraction (a) and average grain size (b) on the cross-sectional surface of the specimens after cogging process in $\mathrm{V}$ - shaped anvils with an angle of $135^{\circ} \times 135^{\circ}$. The reduction ratio of $\varepsilon_{h}=0.70$

The experimental confirmation of the numerical study results is shown in Fig. 9. The strain state was determined using the coordination grid method. The experimental tests were carried out on $\varnothing 80 \times 150 \mathrm{~mm}$ cylindrical specimens made of the Waspaloy alloy, on 
which a $5 \times 5 \mathrm{~mm}$ coordination grid was applied with an accuracy of $0.01 \mathrm{~mm}$. The positions of nodes before and after deformation were measured with an accuracy of $0.01 \mathrm{~mm}$ on a test stand equipped with a toolmaker's microscope coupled with a computer station. The specimens were deformed on a hydraulic press with a pressure of $2.5 \mathrm{MN}$. For the determination of the components of the Cauchy finite strain tensor, the displacement field was approximated with two-parameter polynomials of the sixth order, with the parameters being determined using the least-squares method, while considering the constant volume condition (by the Lagrange multiplier method). A comparative analysis of the effective strain values obtained from the numerical computation and experimentally showed their relatively good agreement (Figs. 9a and 9b).

Experimental measurement of temperature was taken on the surface of deformed specimens using a thermovision camera. The agreement between the computed and measured temperatures obtained for the surface layer (Fig. 9c) suggests that the simulated temperature distributions on the forged band cross-section corresponded to the actual distributions.

Experimental grain size measurement was taken for representative Waspaloy specimens, which had been forged out on $135^{\circ} \times 135^{\circ}-$ angle V-shaped anvils using the following deformation parameters: $\dot{\varepsilon}=0.25 \mathrm{~s}^{-1}, T_{\mathrm{o}}=1323 \mathrm{~K}$ i $\varepsilon_{h}=0.70$ (Fig. 9d). On selected specimens, several measurements of average grain size were taken by the comparative method (complying with standard EN ISO 643:2003). The investigation results for the examined Waspaloy alloy, presented herein, have confirmed the interrelation of the structural changes accompanying the uneven distribution of effective strain within the forging volume.

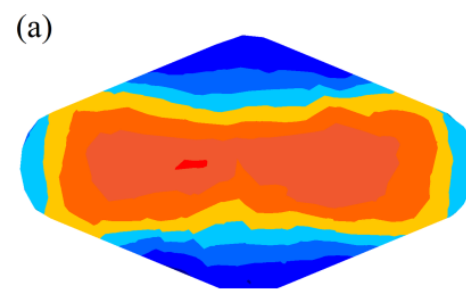

(c)

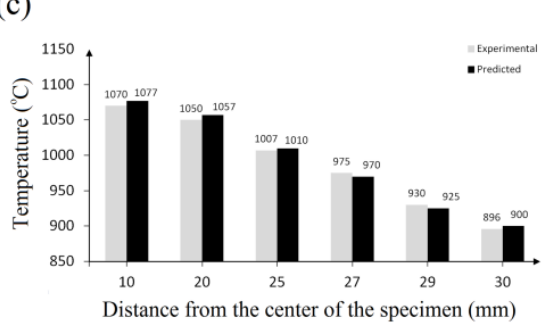

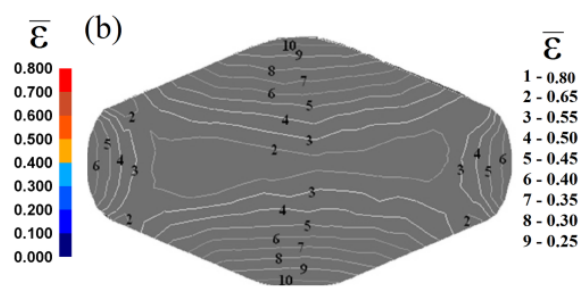

(d)

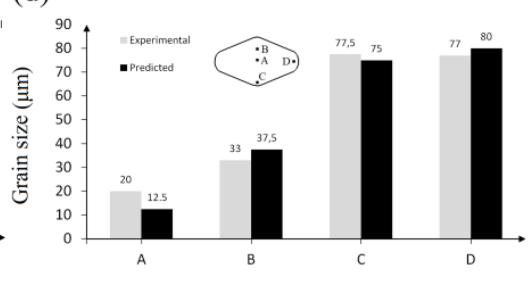

Fig. 9. Comparisons between the predicted and experimentally measured values after the cogging process in $\mathrm{V}$ - shaped anvils with an angle of $135^{\circ} \times 135^{\circ}$ : (a) theoretical distribution of effective strain $\left(l_{w}=0.75 ; \varepsilon_{h}=0.35\right)$, (b) experimental distribution of effective strain $\left(l_{w}=0.75 ; \varepsilon_{h}=0.35\right)$, (c) variation of the temperature at selected points of the deformation zone $\left(l_{w}=0.75 ; \varepsilon_{h}=0.70\right)$, (d) average grain size in the cross-section of the specimens at selected points $\left(l_{w}=0.75 ; \varepsilon_{h}=0.70\right)$ 


\section{Conclusions}

The numerical studies carried out enabled the assessment of the process of cogging the Waspaloy alloy to be made based on the maps of the distributions of effective strain, average stress, temperature and microstructure parameters during simulation of cogging on shaped anvils. Through the selection of the appropriate shape and geometry of anvil working surface and the rational technological parameters, it will be possible to significantly influence the location of maximum effective strain values and the unevenness of effective strain distribution, to eliminate or substantially reduce the tensile stress in the deformation zone, and to refine the structure.

The shaped anvils used in the investigation have proved to be highly effective in the process of cogging the Waspaloy alloy, with the most effective of them being the $\mathrm{V}$-shaped anvils with an angle of $135^{\circ} \times 135^{\circ}$. These tools provided much more favourable conditions for the location of maximum effective strain in the axial forging zone and more intensive microstructure refinement as deformation progressed. During cogging on these anvils, as a result of intensive plastic working of the axial zone, a grain size was obtained in the second technological pass $\left(\varepsilon_{h}=0.70\right)$, which was by $50 \%$ smaller compared to the grain size obtained in cogging on combined anvils. The least effective in this respect appeared to be trapezoid anvils. Large effective strain magnitudes occurring during cogging on $\mathrm{V}$-shaped anvils, with relatively high evenness of their distribution within the forging volume, significantly influence the grain shape and size, which can be varied in a wide range, thus influencing the properties of forgings. Therefore, it is recommended to use these anvils for cogging Waspaloy alloy blanks.

\section{References}

1. Amiri, S. Bruschi, M. H. Sadeghi, P. Bariani, Investigation on hot deformation behavior of Waspaloy. Materials Science \& Engineering A, 562, 77-82 (2013)

2. Y. Wang, Q. Pan, Y. Song, C. Li, Z. Li, Hot deformation and processing maps of X750 nickel-based superalloy. Materials and Design, 51, 154-160 (2013)

3. P. Mannan, A.Kostryzhev, H. Zurob, E. V. Pereloma, Hot deformation behavior of Ni$30 \mathrm{Fe}-\mathrm{C}$ and $\mathrm{Ni}-30 \mathrm{Fe}-\mathrm{Nb}-\mathrm{C}$ model alloys. Materials Science \& Engineering A, 641, 160$171(2015)$

4. J. D. Jaeger, D. Solas, O. Fandeur, J. H. Schmitt, C. Rey, 3D numerical modeling of dynamic recrystallization under hot working: Application to Inconel 718. Materials Science \& Engineering A, 646, 33-44 (2015)

5. Chamanfar, M. Jahazi, J. Gholipour, P. Wanjara, S. Yue, Evolution of flow stress and microstructure during isothermal compression of Waspaloy. Materials Science \& Engineering A, 615, 497-510 (2014)

6. M. S. Chen, Y. C. Lin, K.K. Li, Y. Zhou, A new method to establish dynamic recrystallization kinetics model of a typical solution-treated Ni-based superalloy. Computational Materials Science, 122, 150-158 (2016)

7. E.J. Galindo-Nava, C.M.F. Rae, Microstructure evolution during dynamic recrystallization in polycrystalline nickel superalloys. Materials Science \& Engineering A, 636, 434-445 (2015)

8. L. Chen, Y. Zhang, F. Li, X. Liu, B. Guo, M. Jin, Modeling of dynamic recrystallization behavior of 21Cr-11Ni-N-RE lean austenitic heat-resistant steel during hot deformation. Materials Science \& Engineering A, 663, 141-150 (2016) 
9. Fang, Z. Ji, M. Liu, G. Tian, C. Jia, T. Zeng, Critical strain and models of dynamic recrystallization for FGH96 superalloy during two-pass hot deformation. Materials Science \& Engineering A, 593, 8-15 (2014)

10. J. Wang, J. Dong, M. Zhang, X. Xie, Hot working characteristics of nickel-base superalloy 740 during compression. Materials Science \& Engineering A, 566, 61-70 (2013) 